\title{
DOSE REDUZIDA DE CLETHODIM NO CONTROLE DE PAPUA NA CULTURA DA SOJA, EM FUNÇÃO DA ÉPOCA DE APLICAÇÃO'
}

\author{
NILSON G. FLECK ${ }^{2}$; MARCOS M. DA CUNHA ${ }^{3}$; LEANDRO VARGAS ${ }^{3}$
}

\section{RESUMO}

Foi realiza do um experimento a campo em Eldorado do Sul, RS, no ano agrícola de 1994/95, para avaliar o controle de papuã (Brachiaria plantaginea (Linck) Hitchc.), que ocorreu numa população média de 95 plantas $/ \mathrm{m}^{2}$. Foi avaliado o herbicida clethodim à dose-plena $(120 \mathrm{~g} / \mathrm{ha})$ e à meia-dose $(60 \mathrm{~g} / \mathrm{ha})$. A cultivar de soja utilizada foi RS-7 Jacuí e usado o delineamento experimental em blocos casualizados com quatro repetições. Os tratamentos foram aplicados aos 14, 21, 28 e 35 dias após a emergência da soja (DAE). Foram mantidas testemunhas capinadas, com operações iniciadas nas mesmas épocas de aplicação do herbicida, e uma testemunha infestada durante todo o ciclo da cultura. O controle foi avaliado visualmente, em três ocasiões, através de escala percentual. Os graus de controle de papuã obtidos à dose-plena foram equivalentes entre si quando aplicado nas três primeiras épocas, com eficiência entre 95 e $98 \%$ na última avaliação. A meia-dose mostrou, para as três primeiras épocas de aplicação, resultados semelhantes aos de doseplena, porém em níveis um pouco inferiores, situando-se entre 85 e $95 \%$ o controle obtido na úl ti ma aval iação. O controle do pa puã foi mediano quando clethodim foi aplicado aos 35 DAE, tanto para dose-ple na quanto para meiadose. Quanto ao rendimento de grãos, não houve di ferença estati stic a si gn if ic ativa en tre os tratamentos em suas várias modalidades, embora todos tenham superado a testemunha infestada, com incrementos na produtividade de grãos entre 73 e $105 \%$. O ex perimento permite concluir pela viabilidade da utilização de meiadose de clethodim para o controle de papuã em soja, realizando as aplicações preferencialmente até a quarta semana após a emergência da cultura.

Palavras chave: Glycine max, pósemergência, interferência, Brachiaria plantaginea.

\section{ABSTRACT \\ Reduced rate of clethodim for alexandergrass: control in soybeans as a function of application time.}

A field trial was carried out in Eldorado do Sul, RS, during the 1994/95 growing season to evaluate Alexandergrass (Brachiaria plantaginea (Linck) Hitchc) control, that occ urred with an average population of 95 plants $/ \mathrm{m}^{2}$. The herbicide used was clethodim at full-rate $(120 \mathrm{~g} / \mathrm{ha})$ and at half-rate $(60 \mathrm{~g} / \mathrm{ha})$. The tested cultivar was RS-7 Jacuí and it was used a complete ran domized blocks design with four replicates. The treatments were applied at $14,21,28$, and 35 days after so ybean emergence (DAE). Hand ho eing treatments were included, and started at the same

1 Recebido para publicação em 16/05/95 e na forma revisada em 17/03/97

2 Eng. Agr., Prof. Adjunto da Faculdade de Agronomia da UFRGS, Porto Alegre, RS. Bolsista do CNPq. Caixa Postal 776, CEP 90001- 970, Porto Alegre, RS.

3 Eng. Agr., Aluno do Programa de Pós-Graduação em Agronomia da UFRGS. 
date of herbicide applications. A weeded check was kept during all crop cycle. Control evaluations were visualy performed in three opportunities using percentual scale. The levels of Alexandergrass control got with full herbicide rate were equivalents when clethodim was applied at the three first times. Its efficiency ranged from 95 to $98 \%$ at the last evaluation. Half herbicide rate showed similar trends at the last evaluation, although at lower levels, ranging from 85 to $95 \%$ control for the three first application times. Alexandergrass control was only fair when

\section{INTRODUÇÃO}

As plantas daninhas representam um fator de alta significância na redução da produtividade de grãos da cultura da soja. Esta cultura é, atualmente, a espécie oleaginosa mais cultivada no mundo e com a qual se tem realizado o maior número de testes com herbicidas nos últimos anos. Herbicidas tem sido o maior instrumento de controle de plantas daninhas em soja nos últimos 40 anos (DeFelice et al., 1989). Conforme Foloni (1993), dados estatísticos mostram que es sa cultura é a que mais utiliza herbicidas no Brasil.

Pesquisas em outros países tem mostrado que as doses de aplicação de alguns herbicidas podem ser reduzidas em até $25 \%$ da recomendada nos rótulos, sem prejuízos no controle das plantas daninhas, e sem af et ar dramaticamente o rendimento (O'S ullivam \& Bouw, 1993). També $\mathrm{m}$ no Brasil se tem de monstrado a viabilidade da redução de doses, pelo menos para alguns produtos (Fleck, 1994).

As doses herbicidas constantes nos rótulos dos produtos, estão colocadas, muitas vezes, em níveis mais altos do que os necessários, de tal modo que o controle das plantas daninhas seja efetivamente garantido em amplas condições de ambiente ou de manejo (Devlin et al., 1991). De acordo com King \& Oliver (1992), as doses recomendadas pelos fabricantes pretendem assegurar elevado controle sobre uma grande gama de plantas daninhas, de variada clethodim was applied at 35 DAE at either rate. Grain yield did not show differences between treatments except for weedy check; nevertheless, all of them supplanted the weeded treatment with increments ranging from 73 to $105 \%$. This trial allows to conclude that it is possible to use half-rate of clethodim to control Alexandergrass in soybean, being the application done preferably until the fourth week after soybean emergence.

Key words: Glycine max, postemergence herbicide, interference, Brachiaria plantaginea.

suscetibilidade, em condições que podem não ser as melhores para a atividade do referido produto. Ainda conforme esse autor, a dose do produto herbicida, necessária para o controle de uma espécie, é dependente da idade e estádio de desenvolvimento da planta daninha no momento da aplicação.

Está implícito no conceito do uso de doses herbicidas abaixo das recomen dadas nos rótul os dos produtos, a supressão suficiente da vegetação indesejável, não de forma total, porém sem afetar negativamente a produtividade da cultura. Desse fato decorre que hoje pode-se pensar em abandonar o conceito, que permaneceu válido por long o te mpo, de se obter controle total (o absolutamente limpo), para outro mais prático, de controle apenas suficiente (o economicamente limpo), ficando, dessa maneira, a utilização de herbicidas na amplitude do máximo necessário e do mínimo possível (Zoschke, 1994).

Com o propósito de avaliar a possibilidade de redução de dose do herbicida graminicida de pós-emergência clethodim, foi conduzido um experimento a campo na Estação Ex perimental Agronômica da UFRGS, em El do ra do do Sul, RS, durante a es tação de crescimento de 1994/95. 0 principal alvo desse trabalho experimental foi o de controlar a espécie daninha denominada popularmente de papuã (Brachiaria plantaginea (Link) Hitchc.), que se constitui na principal infestante gramínea das lavouras de soja em toda a região sul do Brasil. 


\section{MATERIAL E MÉTODOS}

A cultivar de soja utilizada no experimento foi RS-7 Jacuí. O experimento foi conduzido em solo podzólico vermelho-escuro, distrófico, classificado como de textura arenofranco-argilosa, com $29 \%$ de argila e $2,0 \%$ de matéria orgânica. $\mathrm{O}$ preparo do solo foi realizado da maneira convencional, por meio de lavração e gradagens de modo a deixá-lo bem preparado para receber a semeadura da cultura. Essas operações também serviram para a incorporação dos adubos necessários à manutenção da fertilidade do solo. A semeadura da soja foi realizada no dia 27 de outubro de 1994, utilizando-se para tal uma semeadora tracionada por trator que estabeleceu fileiras espaçadas de $0,5 \mathrm{~m}$. A emergência das plântulas de soja ocorreu 7 dias após a semeadura, originando uma população média de 38 plantas $/ \mathrm{m}^{2}$. A colheita, por sua vez, foi procedida 165 dias após a emergência das plântulas de soja, em 17 de abril de 1995.

O delineamento experimental utilizado foi o de blocos casualizados com quat ro repetições. O tamanho das parcelas foi de $2,5 \mathrm{~m}$ de largura (5 fileiras) x 5m de comprimento, enquanto que a área útil das parcelas foi de $1,5 \mathrm{~m} \mathrm{x}$ $3,0 \mathrm{~m}$, englobando as três fileiras centrais, desprezando-se as duas fileiras laterais e mais 1 $m$ em cada cabeceira.

Os tratamentos de con trole ao papuã foram aplicados em pós-emergência, em cobertura total da área, aos 14, 21, 28 e 35 dias após a emergência (DAE) da soja. Nessas ocasiões as plantas de papuã encontravam-se nos estádios de três folhas, quatro folhas, quatro afilhos e acima de quatro afilhos, respectivamente. Nessas épocas, foram utilizadas as doses de clethodim $((\mathrm{E}, \mathrm{E})-( \pm) 2-$ [ 1-[[(3-cloro-2-propenil)oxi]imino]propil]-5-[2(etiltio)propil]-3-hidroxi-2-ciclohexeno-1-ona) de $120 \mathrm{~g} / \mathrm{ha}$ (dose-plena) e de $60 \mathrm{~g} / \mathrm{ha}$ (meia-dose). As doses dos herbicidas foram aplicadas através de aspersor costal de precisão, com uma barra com quatro bicos leque (tipo 11003) espaçados entre si em $0,5 \mathrm{~m}$, volume de calda de 2001 /ha e pressão de aspersão de $145 \mathrm{kPa}$. As aplicações dos herbicidas ocorreram sempre pela manhã, no horário entre 8:30 e 9:30h (horário brasileiro de verão), com umidade relativa do ar acima de $70 \%$ e ventos nunca superiores a $5 \mathrm{~km} / \mathrm{h}$.

De modo a estabelecer padrõ es de co mpar ação, fora m mantid as te st em un has ca pi nadas manualmente, cujas operações iniciaram nas mesmas épocas das aplicações dos herbicidas, e ain da uma teste munha infestada durante todo o ciclo da cultura. A espécie daninha objeto do experimento, (papuã), ocorreu numa população média de 95 plantas $/ \mathrm{m}^{2}$, em contagem realizada aos $14 \mathrm{DAE}$, nas parcelas testemunhas infestadas. As plantas daninhas dicotiledôneas, foram controladas com aplicações do herbicida fomesafen, na dose de $250 \mathrm{~g} / \mathrm{ha}$, uma semana após a aplicação com clethodim em cada uma das épocas.

O grau de controle de papuã foi obtido através de avaliações visuais, em número de três, coincidindo com o período entre 2 e 7 semanas após as ap licações he rbicidas. Para tal, foi utilizada uma escala percentual que procurou aferir o controle dessa gramínea em relação aos tratamentos padrões (testemunhas capinadas e infestada). No final do ciclo da soja foi efetuada a colheita manual das plantas da cultura e obtido o rendimento de grãos, o qual foi corrigido para $12 \%$ de umidade.

Os dados obtidos foram submetidos à análise da variância pelo teste $\mathrm{F}$ e as médias dos tratament os comparadas entre si pelo tes te de Duncan, ambas ao nível de significância de 5\% de probabilidade. Também foi procedida análise dos tratamentos através de contrastes ortogonais.

\section{RESULTADOS E DISCUSSÃO}

Com relação ao controle da planta da ninha alvo (papuã), ve rificou-se que os tratamentos herbicidas em dose-plena (120g/ha) foram equivalentes entre si quando aplicados nas três prime ir as ép oc as $(14,21$ e 28 DAE), alcançando eficiência entre 95 e $98 \%$ quando da última avaliação visual. Já na aplicação de doseplena aos 35 DAE, o grau de controle situou-se 
TABELA 1. Avaliação do controle de papuã (Brachiaria plantaginea) com o herbicida clethodim em soja em função de dose e época de aplicação, EEA/UFRGS, Eldorado do Sul, RS, 1994/95.

\begin{tabular}{|c|c|c|c|c|c|}
\hline \multirow[t]{2}{*}{ Tratamentos } & \multirow[t]{2}{*}{ Dose (g/ha) } & \multirow{2}{*}{$\begin{array}{c}\text { Época de } \\
\text { aplicação DAE }\end{array}$} & \multicolumn{3}{|c|}{ Avaliações de controle de papuã ${ }^{2}$} \\
\hline & & & 1 & 2 & 3 \\
\hline 01. Testemunha capinada & -- & -- & $100 a^{3}$ & $100 \mathrm{a}$ & $100 \mathrm{a}$ \\
\hline 02. Clethodim & 60 & 14 & 89 bcd & $89 \mathrm{bc}$ & $85 \mathrm{c}$ \\
\hline 03. Clethodim & 60 & 21 & $85 \mathrm{~cd}$ & $93 a b$ & $95 \mathrm{ab}$ \\
\hline 04. Clethodim & 60 & 28 & $82 \mathrm{~d}$ & $83 \mathrm{c}$ & $93 \mathrm{~b}$ \\
\hline 05. Clethodim & 60 & 35 & $56 \mathrm{e}$ & $56 \mathrm{~d}$ & $74 \mathrm{~d}$ \\
\hline 06. Clethodim & 120 & 14 & $95 \mathrm{ab}$ & $91 \mathrm{~b}$ & $95 \mathrm{ab}$ \\
\hline 07. Clethodim & 120 & 21 & $94 \mathrm{ab}$ & $95 \mathrm{ab}$ & $97 \mathrm{ab}$ \\
\hline 08. Clethodim & 120 & 28 & $91 \mathrm{bc}$ & $89 \mathrm{bc}$ & $99 a b$ \\
\hline 09. Clethodim & 120 & 35 & $58 \mathrm{e}$ & $58 \mathrm{e}$ & $86 \mathrm{c}$ \\
\hline 10. Testemunha infestada & 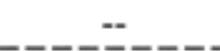 & $=$ & $0 \mathrm{f}$ & $0 \mathrm{e}$ & 0 e \\
\hline Coeficiente de variação $(\%)$ & & & $\overline{6}, \overline{4}$ & $\overline{6}, \overline{2}$ & $\overline{4}, \overline{7}$ \\
\hline
\end{tabular}

A utilização de meia-dose $(60 \mathrm{~g} / \mathrm{h}$ a) (Tabela 1), mostrou tendência semelhante aos resultados obtidos com a utilização de dose-plena, porém alca nçando patamares inferiores, com o nível de controle situando-se na faixa entre 85 e $95 \%$ por ocasião da última avaliação, considerando-se as três primeiras épocas de aplicação. Já para a quarta época de aplicação (35 DAE), o grau de controle do papuã foi nitidamente inferior (apenas 74\%), em função do estádio avançado de desenvolvimento das plantas de papuã que na ocasião se encontravam com mais de quatro afilhos. Kunz \& Dapont (1995), comparando gram inicidas de pós-emergência, entre os quais clethodim $(96 \mathrm{~g} / \mathrm{ha})$ relatam que o controle obtido para a aplicação feita aos 32 DAE, quando o papuã apresentava-se com quatro afilhos, também foi inferior à aplicação feita aos 24 DAE, quando o papuã estava no estádio de um afilho. Sabe-se que uma das premissas básicas do uso de dose reduzida de herbicida é sua aplicação sobre plantas daninhas nos estádios iniciais de crescimento, período em que sua suscetibilidade é máxima e sua recuperação é mínima (Klingaman et al., 1992).

Ainda, em relação ao uso de dose reduzida de clethodim, pode-se constatar que a aplicação aos 14 DAE mostrou, no final das avaliações, um grau de controle inferior aos alcançados nas aplicações de 21 e 28 DAE. Isso se deve principalmente ao fato de que a aplicação do he rbi cida aos 14 DAE permitiu novas germinações de papuã, uma vez que as plantas de soja ainda não fechavam completamente as entre linhas. A espé cie daninha papuã se caracteriza por uma grande produção de dis semínulos e uma germin ação distribuída ao longo do ciclo da cultura (Martins, 1994). Já nas aplicações posteriores, tal ocorrência não foi importante, em função da própria competição exercida pela cultura da soja, a qual cobriu to talmente os espaços entre as fileiras. Isso ressalta a importância do efeito auxiliar do método cultural como complemento ao controle químico das plantas daninhas.

Em de corrência desses resultados, constata-se que dose-plena ou meia-dose de clethodim, aplicados aos 14, 21 ou 28 DAE, 
controlam satisfatoriamente a espécie daninha em estudo, ressaltando-se porém que a aplicação de meia-dose aos 14 DAE apresentou um grau de controle inferior devido à reinfestação.

Quanto ao rendimento de grãos, não houve diferença estatística entre os tratamentos herbicidas e capinados testados em suas várias modalidades (Tabela 2). Steckel et al. (1990), avaliando o controle de plantas daninhas dicotiledôneas em soja, também não encontraram diferenças nos rendimentos, tanto para doses plenas como para doses reduzidas, apesar dos controles um pouco inferiores para as doses reduzidas. Fleck (1994), em experimentos visando controlar papuã com haloxyfop, obteve rendimentos de grãos semelhantes para dose plena e reduzida. Por outro lado, constatou-se que todos os tratamentos superaram a testemunha infestada com incrementos na produtividade de grãos entre 73 e $105 \%$. A interferên cia oc asionada pela infestação de plantas de papuã no tratamento infestado reduziu a produtividade da cultura em níveis que alcançaram até $51 \%$ (Tabela 2). A esse respeito, Fleck (1995), comparando 35 pares de parcelas, constituídos de tratamentos capinados manualmente durante todo o ciclo e de tratamentos naturalmente infestados por ess a espécie daninha, relata reduções variáveis do rendimento de grãos de soja entre 40 e $80 \%$, para a maioria dos casos.

TABELA 2. Rendimento de grãos de soja tratada com o herbicida clethodim em função de dose e época de aplicação, EEA/UFRGS, Eldorado do Sul, RS, 1994/95.

\begin{tabular}{|c|c|c|c|}
\hline Tratamentos & Dose (g/ha) & $\begin{array}{c}\text { Época de aplicação } \\
\text { DAE }^{1}\end{array}$ & $\begin{array}{c}\text { Rendimento de grãos } \\
\text { (kg/ha) }\end{array}$ \\
\hline 01. Testemunha capinada & -- & 14 & $4885 \mathrm{a}^{2}$ \\
\hline 02 . Testemunha capinada & -- & 21 & $4430 \mathrm{a}$ \\
\hline 03. Testemunha capinada & -- & 28 & 4542 a \\
\hline 04. Testemunha capinada & - & 35 & 4298 a \\
\hline 05. Clethodim & 60 & 14 & $4220 \mathrm{a}$ \\
\hline 06. Clethodim & 60 & 21 & $4600 \mathrm{a}$ \\
\hline 07. Clethodim & 60 & 28 & $4256 \mathrm{a}$ \\
\hline 08. Clethodim & 60 & 35 & $4112 \mathrm{a}$ \\
\hline 09. Clethodim & 120 & 14 & $4580 \mathrm{a}$ \\
\hline 10. Clethodim & 120 & 21 & 4554 a \\
\hline 11. Clethodim & 120 & 28 & $4265 \mathrm{a}$ \\
\hline 12. Clethodim & 120 & 35 & 4347 a \\
\hline 13. Testemunha infestada & - & - & $2383 \mathrm{~b}$ \\
\hline Coeficiente de variação $(\%)$ & & & $1 \overline{2}, \overline{7}$ \\
\hline
\end{tabular}

A comparação entre agrupamentos de produtividades para os tratamentos capinado, doseplena e meia-dose de clethodim, indicou reduções de $2,2 \%$ para dose-plena e de $5,3 \%$ para a meiadose, respectivamente, em relação à primeira modalidade (capinado) (Tabela 3). Esses dados analisados através de contrastes ortogonais, não mostraram diferenças significativas. De acordo com Van Acker et al. (1993), a dose herbicida pode ser reduzida se a aplicação for realizada durante o período crítico de competição das plantas daninhas com a cultura, desde que as ervas não tenham atingido estádio de crescimento muito avançado. 
TABELA 3. Resultados agrupados para avaliações de controle de papuã (Brachiaria plantaginea) $e$ rendimento de grãos de soja em função de doses de clethodim, EEA/UFRGS, Eldorado do Sul, RS, 1994/95.

\begin{tabular}{|c|c|c|c|c|c|}
\hline \multirow[t]{2}{*}{ Tratamentos } & \multicolumn{3}{|c|}{ Avaliações de controle (\%) } & \multirow{2}{*}{$\begin{array}{l}\text { Rendimento de } \\
\text { grãos (kg/ha) }\end{array}$} & \multirow{2}{*}{$\begin{array}{c}\text { Relação } \\
(\%)\end{array}$} \\
\hline & 1 & 2 & 3 & & \\
\hline Testemunha capinada & 100 & 100 & 100 & 4359 & 100 \\
\hline Clethodim dose plena & 84 & 84 & 94 & 4438 & $-2,2$ \\
\hline Clethodim meia dose & 78 & 80 & 86 & 4298 & $-5,3$ \\
\hline
\end{tabular}

' Avaliação 1 feita aos 14 dias após a aplicação. Avaliação 2 feita aos 14 dias após a última aplicação. Avaliação 3 feita aos 28 dias após a última aplicação.

Com relação às épocas de aplicação das medidas de controle do papuã, constatou-se que, em comparação à produtividade média obtida aos 14 DAE, houve reduções de $0,7 \%, 4,5 \%$ e $6,8 \%$ com o atraso na implementação das medidas de controle da espécie infestante para 21, 28 e 35 DAE (Tabela 4). Essas diferenças também não atingiram nível de significância estatística quando comparadas por contrastes or to gonais. Os resultados indicam uma certa hierarquia e estão de acordo com estudos sobre período crítico de competição de plantas daninhas com soja realizados por Spad ot to et al. (1994) que ressaltam o período entre 21 e 30 DAE como o mais crítico.

Acredita-se que não ocorreram diferenças significativas entre os tratamentos de controle ao papuã, para a variável produtividade de grãos, uma vez que a população de plantas de soja esteve próximo à ideal, e o espaçamento entre fileiras, foi adequado, permitindo alto poder competitivo da cultura em relação à infestante, além da ocorrência de condições climáticas favoráveis ao crescimento da cultura, especialmente chuvas suficientes e bem distribuídas durante todo o ciclo, mas em especial durante a fase reprodutiva.

Os resultados do experimento permitem concluir pela viabilidade em se utilizar apenas meia-dose do herbicida graminicida de pósemergência clethodim para controlar a espécie daninha papuã na cultura da soja. A utilização de dose-plena do herbicida pode ser efetuada entre 2 e 4 semanas após a emergência da soja, mas se recomenda que o uso de meia-dose de clethodim seja realizado entre 3 e 4 semanas após a emergência da cultura para ser obtido nível satisfatório de controle. A aplicação do herbicida 5 semanas após a emergência da soja deve ser evitada, especialmente ao se optar pela aplicação de meia-dose de clethodim.

TABELA 4. Resultados agrupados para avaliações de controle de papuã (Brachiaria plantaginea) $e$ rendimento de grãos de soja em função da época de aplicação de clethodim, EEA/UFRGS, Eldorado do Sul, RS, 1994/95.

\begin{tabular}{|c|c|c|c|c|c|}
\hline \multirow{2}{*}{$\begin{array}{c}\text { Época dos tratamentos } \\
\text { (DAE) }^{1}\end{array}$} & \multicolumn{3}{|c|}{ Avaliações de controle $(\%)^{2}$} & \multirow{2}{*}{$\begin{array}{l}\text { Rendimento de } \\
\text { grãos (kg/ha) }\end{array}$} & \multirow{2}{*}{$\begin{array}{c}\text { Relação } \\
(\%)\end{array}$} \\
\hline & 1 & 2 & 3 & & \\
\hline 14 & 92 & 90 & 90 & 4562 & 100 \\
\hline 21 & 89 & 93 & 96 & 4528 & $-0,7$ \\
\hline 28 & 86 & 85 & 95 & 4355 & $-4,5$ \\
\hline 35 & 57 & 57 & 80 & 4253 & $-6,8$ \\
\hline
\end{tabular}

1 Dias após a emergência da soja.

${ }^{2}$ Avaliação 1 feita aos 14 dias após a aplicação. Avaliação 2 feita aos 14 dias após a última aplicação. Avaliação 3 feita aos 28 dias após a última aplicaçăo. 


\section{LITERATURA CITADA}

DEFELICE, M.S., BROWN, W.B., ALDRICH, R.J., SIMS, B.D., JUDY, D.T., GUETHLE, D.R. Weed control in soybeans (Glycine max) with reduced rates of postemergence herbicides. Weed Sci., v.37, n.3, p.365-374, 1989.

DEVLIN, D.L., LONG, J.H., MADDUX, L.D. Using reduced rates of postemergence herbicides in soybeans (Glycine max). Weed Technol. parcelas, v.5, n.4, p.834-840, 1991.

FLECK, N.G. Doses reduzidas de herbicidas de pós-emergência para controle de papuã em soja. Planta Daninha, v.12, n.1, p.21-28, 1994.

FLECK, N.G. Redução da produtividade da soja por interferência de papuã e benefícios al cançad os at ra vés do controle de sua infestação. In: CONGRESSO BRASILEIRO DA CIÊNCIA DAS PLANTAS DANINHAS, 20, 1995. Resumos... Florianópolis: SBCPD, 1995, p.100-101.

FOLONI, L.L. Impacto ambiental do uso de herbicidas a nível de Brasil. Cien. Plan. Dan., v.1, n.2, p.11-22, 1993.

KING, C.A., OLIVER, L.R. Application rate and timing of acifluorfen, bentazon, chlorimuron, and imazaquin. Weed Technol., v.6, n.3, p.526-534, 1992.

KLINGAMAN, T.E., KING, C.A., OLIVER, L.R. Effect of application rate, weed species, and stage of growth on imazethapyr activity.

Weed Sci., v.40, n.2, p.227-232, 1992.
KU NZ, R.P., DA PONT, V.A. Avaliação da eficiência de propaquizafop no controle de Brachiaria decunbens na cultura da soja (Glycine $\max (\mathrm{L})$ Merrill). In: CONGRESSO BRASILEIRO DA CIÊNCIA DAS PLANTAS DANINHAS, 20, 1995. Resumos... Florianópolis: SBCPD, 1995, p.5455.

MARTINS, D. Interferência de capim-marmelada na cultura da soja. Planta Daninha, v.12, n.2, p.93-99, 1994.

O'SULLIVAN, J., BOUW, W.J. Reduced rates of postemergence herbicides for weed control in sweet corn (Zea mays). Weed Technol., v.7, n.4, p.995-1000, 1993.

SPADOTTO, C.A., MARCONDES, D.A.S., LUIZ, A.J.B., SILVA, C.A. da. Determinação do período crítico para pre ve nção da interferência de plantas daninhas na cultura da soja: uso do modelo Broken-Stick. Planta Daninha, v.12, n.2, p.59-62, 1994.

STECKEL, L.E., DEFELICE, M.S., SIMS, B.D. Integrating reduced rates of postemergence herbicides and cultivation for broadleaf weed con trol in soybeans (Glycine max). Weed Sci., v.38, n.6, p.541-545, 1990.

VAN ACKER, R.C., SWANTON, C.J., WEISE, S.F. The critical period of weed control in soybeans (Glycine max). Weed Sci., v.41, n.2, p.194-200, 1993.

ZOSCHKE, A. Toward reduced herbicide rates and adapted weed man agement. Weed Te ch nol., v. 8, n. 4, p. 376-38 6, 1994. 